\title{
The phenomenon of digitalization of the legal business education
}

\author{
Andrey Sadkov ${ }^{1}$, Natalia Kvitsinia ${ }^{2 *}$, and Viktoria Sandalova ${ }^{3}$ \\ ${ }^{1}$ Volgograd State University, University Avenue, 100, Volgograd, Russia, e-mail: sadkov@volsu.ru, ORCID 0000-0002-6148-0576 \\ ${ }^{2}$ Volgograd State University, University Avenue, 100, Volgograd, Russia e-mail: gimchp@volsu.ru, ORCID 0000-0002-6538-9796 \\ ${ }^{3}$ Volgograd State University, University Avenue, 100, Volgograd, Russia, e-mail: sandalova@volsu.ru, ORCID 0000-0001-8600-4974
}

\begin{abstract}
This article attempts to consider the phenomenon of digitalization of education in the construction of a digital economy, to identify the most significant problems, risks, as well as the vector of modification of the educational process from the standpoint of legal and ethical regulation. Results: according to the results of the study, the authors made proposals to improve state standards in the field of law in terms of updating competencies in the context of digitalization of the economy, identified promising educational innovations, proposed ways to modernize the educational process. Conclusion: the system of legal business education is in a state of transformation, requires updating of state standards in the field of training "jurisprudence", updating the curriculum, content and typology of seminars, as well as the introduction of educational innovations in the educational process.
\end{abstract}

\section{Introduction}

Digitalization of education is a topic that is currently under discussion. Special portals dedicated to digital education (for example: http://www.digital-edu.ru/; http://window.edu.ru) have become very popular, bloggers have become more active, subject magazines have begun to appear. Audience activity is due to a number of objective and subjective factors. Let's consider some of them.

First of all, lawyers were forced to go into problems of digitalization due to the state programs both in the field of economics and in the field of education itself [1]. Among these program documents, a special place is taken by the program "Digital Economy of the Russian Federation" (hereinafter referred to as the Digital Economy Program) approved by the Government of the Russian Federation No. 1632-p dated July 28, 2017, adopted to implement the Information Society Development Strategy in the Russian Federation for 2017-2030 years (approved by Decree of the President of the Russian Federation dated May 9, 2017 No. 203). One of the main directions of the Digital Economy Program, which attracts attention, is the "personnel and education" direction, which envisages the creation of key conditions for the training of personnel in the digital economy and the improvement of the educational system itself.

The development of the Concept is determined by the growing contradictions between the objective needs of the digital economy and the established tradition of training lawyers in the higher education system. The necessity of its appearance is dictated by the importance of the task of creating a fundamentally new mechanism of training legal personnel for the needs of the digital economy, the desire to ensure the employment of graduates in conditions of tough competition in the legal services market.

Russian practice shows that in the past two years there has been a tendency to actively introduce digital technologies into the Russian economy, as evidenced by the program "Digital Economy of the Russian Federation". According to experts, digital transformation is a new reality, in which an important place is given to digital data, which determines the development of production. The ability to work with Big Data brings the country to a high competitive level. New technological prospects directly affect legal professions, which are gradually changing both in Russia and abroad.

Secondly, the modernization of education is also necessary because a new generation of digitalnatives has grown up, whose representatives demonstrate a tendency to use new technologies in their daily lives. At the same time, research by IT specialists reveals the use of appropriate technologies not only in the professional sphere, but also for socialization and communication. Consequently, the digitalization of education will make it more adapted to the modern audience, which will lead to an increase in the competitiveness of the university in the education market, the creation of additional value and the involvement of students.

In addition, we shall notice, that today such parameters as the level of technical equipment of student workplaces in libraries, the availability of free access for students and teachers to information resources that ensures the educational process and research work, open

\footnotetext{
* Corresponding author: gimchp@volsu.ru
} 
wireless network, wireless network coverage in educational and administrative premises of the university, access speed in the Internet wireless network - are important for the state and public professional accreditation of the educational organization.

The noted and other arguments indisputably testify to the need of digitalization of legal business education, which implies the solution of other tasks associated with this goal [2]. So, in order to equip future lawyers with "advanced" knowledge, it is necessary to develop personal educational pathways for students, to form the basic competences of a lawyer, to modify the certification system that minimizes the ability to reproduce ready-made knowledge. It is important to ensure the education of a harmoniously developed and socially responsible person.

The Association of Solicitors in England and Wales (The Law Society) has published a report on the future of the legal profession. Experts believe that in the next five years, all participants in the legal market are expected to see global changes associated with the emergence of robotic substitutes for lawyers providing low-cost legal services. Competition will affect not only the solution of simple tasks related to conciliation procedures in the field of economic disputes, but also will affect complex legal issues. The tendency to change the situation not in favor of practicing lawyers is already developing. The software that can read and correctly interpret legal texts, helping in seconds to find solutions to complex legal issues has been developed.

Programs have been created, such as Leverton, which recognizes 18 languages and is capable of self-learning. With each new document, it builds an algorithm of the original legal solution, identifies errors, prepares reports on the terms of the agreement. Leverton is quickly learning to understand the complex legal language of contracts. Artificial intelligence "Watson" from IBM is capable of self-learning and development. In a few seconds, it makes an analysis of tens of thousands of legal documents, regulatory and judicial acts and prepares an original legal opinion. This software answers legal questions, forms claims and contracts, based on current practice.

British experts believe that thanks to technologies, including big data, online justice, the availability of justice will increase in the next five years and the cost of legal services will decrease, which threatens the loss of legal services markets for law firms specializing in these topics.

On the Internet, bot programs are widely used to assist in filling out various legal documents [3]. The bot is able to form claims for different life situations. An Australian law firm has presented an online consultation service with a lawyer. The robot program is able to make a speech for the court hearing and to answer questions during a conversation with a user.

In February 2018, the first robot lawyer specializing in consumer protection began operating in Russia. The robot is able to understand human speech, recognize abbreviated oral text, respond competently and provide high-quality legal advice.
The Russian law enforcement practice already uses the service of robots, which processes claims of individuals in Sberbank, which allowed to reduce about 3 thousand lawyers in this department. Mobile applications are being actively introduced to enable users to fill in and submit applications to appeal against parking fines. Similar programs for divorce proceedings work.

\section{Problem Statement}

The current regulation of the educational process makes it difficult to personalize education, introduce personal educational pathways into the educational process, allow students to acquire the necessary knowledge and skills in the field of digital technologies. In the conditions of existing educational standards and educational control procedures, building personal educational pathways for a significant number of trainees becomes very difficult. In accordance with the trends in the modern economic sphere and the tasks in the field of digitalization of society, the creation of a new generation of lawyers requires a change in the educational paradigm that determines the need for:

- developing new educational standards and training programs for law students aimed at the development of general digital literacy, forming digital competence, allowing law graduates to freely integrate into the digital economy [4];

- providing opportunities for educational institutions of higher education, providing training for lawyers, to develop and implement in the educational process the basic educational programs for students, taking into account the specific needs of the digital economy;

- making a competitive selection of educational organizations conducting legal training in order to empower them to develop competence models of lawyers capable of functioning in the digital environment, in this regard, cooperation with educational institutions of economic and technical profiles is possible, which will ensure interdisciplinary development of the necessary knowledge and skills;

- developing professional standards for legal professions, taking into account the digital competence of candidates for lawyers capable to act effectively in the digital economy, in this task, the main organizing role can be taken by associations and unions of lawyers with the coordinating role of the Association of Russian Lawyers [5];

- training of a new generation of teachers who are able to develop and solve the problems of legal support of the digital economy, to create educational content, including its mobile version, relevant to the market of digital services, using digital tools in the 
electronic textbooks and manuals with video and audio support;

- creating a program of teaching staff retraining in law schools, adapted to innovative introduction of modern digital technologies in the educational process;

- updating of educational technologies with the introduction of personal learning pathways into the educational process, allowing students to choose formal and informal ways of forming basic digital competencies, to introduce new forms of certification of graduates with the involvement of employers who have experience in trading on digital platforms with digital products and startups;

- aligning the material and technical base as well as information and educational environment of legal educational institutions with the requirements of the society digitalization;

- developing relevant educational content that meets the needs of the educational market, along with the preparation of electronic copies of text information (digitized electronic textbooks) and the creation of a new generation of programmable textbooks (bots, robots-textbooks), tied to the basic educational program, operating in an interactive mode, able to update the legal framework, judicial practice, to form audiovisual information, update it as it becomes obsolete [6];

- changing in the assessment of the quality of training legal educational institutions graduates, allowing to identify the level of their digital competence, the ability to independently integrate and function in the digital economy;

- creating a system of motivation of students of law schools in the development of digital competencies for this: a) to introduce appropriate certification standards of the level of competencies in the digital economy for graduates of law schools, to use interested employers who can remotely participate in their certification with subsequent employment; b) to implement the mechanism of scholarships (grants) for students who have successfully mastered the educational programs of the digital economy, using the achievements of the leaders of the Russian market - Sberbank, Severstal, Norilsk Nickel, Rosgosstrakh and others with experience of continuous training of their employees [7];

- introducing a system of benefits for law firms engaged in practical training of law students in digital competencies;

- preparing proper level of knowledge and skills in digital technology of students in their training process and at the stage of their final exams.

\section{Research Questions}

The active introduction of digital technologies leads to the reorganization of the educational process, which will be largely based on the use of artificial intelligence technologies [8]. However, law enforcement, which involves a competency-based approach, is essentially a creative function. Despite the planned digital transformation of education, the relevant ministries have not defined clear objectives, especially for the Humanities, including law. Lawyers in higher education are trained according to standards designed for consumers of legal personnel of the old technological structure.

It seems that the defining factor of the new business education model should be operational relations with the labor market, which will prevent the threat that training will no longer be in demand. The existing legal framework makes it possible to establish such relations. The fact is that the standards involve students to undergo practical training, while the practical skills acquired during it are determined by the main educational university programs. It seems that such a practice should be systemically structured and involve a gradual immersion in the profession of a business lawyer. The practice of replacing the collection of materials for writing a master's thesis or obtaining teaching skills, participating in the university's admission campaign, etc., is also unacceptable. In addition, it makes sense to follow the standards of laboratory courses both outside universities and direct employers that integrate students into the profession as much as possible.

Since the standards require that universities update their educational programs annually, taking into account the development of economics and technology, it is necessary to include in the variable part of the educational program the possibility of studying the legal aspects of the digital economy as a practical course that deals with legal support of high-tech projects.

It is necessary to reverse the existing low academic mobility of students and teachers in Russia - a situation that is rare, and sometimes directly prohibited in most leading scientific countries. The university should strive for the alternation of languages, which will contribute to the deepening of students ' understanding and broaden their horizons, as well as the enrichment of cultural experience and outlook.

\section{Purpose of the Study}

Digitalization of education is possible due to the fact that several general-purpose technologies were developed and implemented simultaneously [9], which created ideal conditions for development: mobile devices, cloud computing, big data analytics platform, artificial intelligence, biometric technology, and most importantly - the Internet. 
In this aspect, the phrase "digitalization of education" should be used to describe a transformation that goes further than simply replacing an analog or physical resource with a digital or informational one. The simplest example: textbooks do not just turn into ebooks, but represent a set of interactive experiences.

It is quite possible that digitalization will take its place in a number of real discoveries, such as, for example, printing, which, being essentially a purely technical invention, became a catalyst for human progress, which determined the development of civilizations of the second half of the past millennium.

\section{Research Methods}

The scientific article is based on the use of both general scientific and private scientific methods. General scientific methods include: dialectical method, logical methods (analysis, synthesis, induction and deduction). Special methods include comparative and formal legal methods. When analyzing the current legislation, the following interpretation methods are consistently used: literal, systematic, historical, doctrinal, comparative legal. The methodological basis of the article is the interrelated methods, means and methods of cognition of social phenomena. The article uses such general scientific methods and methods of cognition as induction and deduction, analysis and synthesis, analogy, comparison, etc. A special attention was paid, in particular, to the method of comparative law, system and functional approaches, as well as the formal legal method and forecasting method.

\section{Findings}

\subsection{Progressive educational tools}

In general, today, as DigitalMcKinsey experts rightly point out, methods used in Russian education, training formats, educational programs, approaches to interacting with potential employers require adaptation to the needs of the digital economy so that the educational system can continue to train competitive personnel [10].

The positive aspects that have already been introduced include online courses and even remote mega-universities, which provide an opportunity to obtain higher education in the most favorable conditions for the student (at the place of residence, etc.). Thus, according to the State Program "Development of Education", it is planned to increase the number of online courses to 2500 by 2019 , and by 2020 to 3500 [11].

Some Russian universities already work both within the framework of Western educational platforms (for example, the Higher School of Economics places its courses on Coursera), and with the use of domestic software products. The most famous of them is the National Open Education Platform (https://openedu.ru/), where, on September 1, 2018, there were 310 online courses in various areas of training. At the same time, in the discipline 40.00.00 Jurisprudence there were 21 online courses, of which it seems that only the web development of Tax Law (St. Petersburg State University) and Legal Support for Startups (Moscow State University V. Lomonosov) refer to business education. Thus, the shortage and need for online courses that provide distance learning of business law disciplines are obvious.

But the flow of other educational innovations may be truly inexhaustible: learning through social media (such as Twitter and Facebook), virtual simulators, mobile gaming applications, educational chat bots. Crowdlearning (appeal to the public) is seen as a promising modification, where students, amateurs and experts exchange ideas, generate and discuss content, solve problems, vote for the best solutions. A classic example of the work of the public is Wikipedia, which is created and constantly updated by joint efforts. Possible areas of crowdsourcing in business education include collecting and selecting empirical material, creating opportunities for exchanging opinions and discussing works online and providing opinions and data for use in projects and research.

In addition, the use of blockchain technology provides ample opportunity for education in general and business education in particular. With its help, it is possible to provide a transition from the centralized storage of students' academic achievements to a more democratic model, within which such records are kept by a wide range of participants in the system. The blockchain technology allows any participant to add new entries into a single chain of digital events, for example, the number of points, to store educational documents, written papers and examination papers, tests and the results. Students can also receive reputation points for performing intellectual tasks, such as checking business projects or scientific articles of other students, or pass on several reputation points to encourage the creation of an idea to another student or a teacher. Opening new opportunities for trading with a reputational currency, the use of blockchain technology creates a relationship to business training as to the object of sale [12].

\subsection{Risks of digital education}

The lawyer of the digital age is a person who is able to work not only in the real but also in the virtual space. The electronic environment, integrating into the social world, changes the habitual human habitat, transferring it to cyberspace. Digitalization and virtualization, which have become part of the digital revolution, create many previously non-existent ideological, moral, ethical problems, partly generated by the information environment, which plays the role of social communication and, at the same time, levels out the accepted moral ideals not only in a single professional environment, but also in society as a whole.

It can be stated that the network space has captured a certain part of society, in this regard, the traditional morality and culture have changed significantly, selfconsciousness based on other virtual values has appeared 
[13]. The network culture of interpersonal relations has affected the spheres of spirituality, religion and education. In this regard, the issue of ethical and moral aspects of training legal personnel has become more urgent.

The virtual environment has transformed the valuesemantic basis of legal education and the information needs of students. Universal access to knowledge has given rise to the prospect of personalized learning. Under the influence of the information environment, a new type of students is formed, independently determining their educational trajectory, using the potential of self-education and self-development, connecting together their studies and work on the basis of network educational technologies and academic freedom in choosing content, forms, methods, place and time of training.

The learning process goes to remote sites. Between the student and the teacher there is a "technical intermediary" in the form of an electronic program, electronic platform, bot, robot or other product of the digital revolution. In cyberspace, there is a new morality in the relationship between a learner and a teacher. Being in a virtual space where electronic data circulate and there is no morality, a learner loses social orientation. Training a lawyer in such conditions is fraught with a change in his perception of objective reality, a reassessment of traditional values, which ultimately generates new ethics of relations not only between the student and the teacher, but also between the student and the potential employer, who can see the candidate for the position only in a virtual aspect.

Managing the educational process remotely, the teacher sometimes does not know who he is dealing with. His role as a mentor is lost and goes into a different quality. The teacher has a new technological function of the communicator, uniting students into groups, and groups are formed not by them, but by the interest of students in the academic discipline. Remote technology changes the social status of the teacher. Academic degree and title, which were previously indicators of the level of teacher training, come to the background. The teacher is in demand if he is interesting to the student.

The virtual environment transformers the status of the learner [14]. He becomes a consumer of information that is identified in the digital space as a virtual object, not a person. Accordingly, the ethics of relations change, in this case, not a person communicates with a person, but a digital image with an object. The student does not feel emotions towards the teacher, this in turn changes the attitude to the subject being studied, as in the traditional system of education the interest in the subject is largely formed by the personality of the teacher.

Students have to independently assess educational content, make a decision about the reliability of the information received, which turns into an effective form of influence on socio-cultural and moral regulatory mechanisms. The student chooses the content, which does not always coincide with the teacher's worldview. The use of the information necessary for students forms the system of activity motives and is the basis for the development of professional competencies.
The transition to the depersonalization of the student is one of the side effects of the digital revolution, which will lead to a change in unformed in psychologically unformed student. In this regard, along with professional competencies at the lawyer's training stage, it is necessary to form the competence of "information and digital culture", an integral part of which is digital literacy. It is the orientation in the digital space that makes it possible to understand how digital reality works, how a person interacts with digital technologies, what moral qualities, as socially significant in the professional activity of a graduate of a legal educational institution, need to be developed in a digital environment.

The digitalization of society and the economy, leads to a change of priorities in the choice of professions, the decline of social demand for education in the Humanities in general and Law in particular. The number of firstyear students studying in Moscow in the field of digital technologies in 2018 increased to 19.6 thousand people. This is $11 \%$ more than in 2017 . The number of vacancies for IT specialists in Moscow exceeded 20 thousand - this is $25 \%$ more than a year earlier [15].

The current practice makes it possible to assume that the demand for professions in the information technologies and digital sphere will dramatically exceed supply in the near future; their prestige in society will automatically rise. There will be a gap between the level of knowledge and skills of people who received technical education and people graduated from humanitarian and law schools. The elite within the professional community, skilled in information technologies (knowledge-class) and limiting their circle from the inflow of differently-minded will be formed. There will be a new morality based on professional affiliation.

It is possible to avoid this scenario if integrate academic disciplines (modules) providing digital competences into educational training programs for lawyers and align taking into account the intellectual parameters of graduates of higher education institutions specialized in IT with graduates of the humanitarian and legal educational institutions and, thus, increase their sustainability in the labor market. At the same time, the prestige of legal professions will remain. As early as 2019, large companies in the non-technology sector will launch their own machine learning laboratories, which will allow people with no technical education to be included in the training.

The digital network space largely depends on the ethics of relationships between people, machines and nature. Human desire to accelerate the process of digitalization of all socio-economic parts of life, including education, can work in the opposite direction and generate voluntary social isolation of people.

If the traditional form of education consolidated the student community, socializing all students, the digital, distance learning, on the contrary, isolates students from each other. In cases of training lawyers, this is a negative factor, since one of the qualities of lawyers is the ability to communicate in society. The development of communicative competences in real and virtual spaces is 
one of the tasks of legal education. Therefore, there is an urgent need to create a virtual, digital ethics as a field of applied ethics, including moral and philosophical reflection and moral evaluation of virtual communication, to prepare the theoretical basis of the norms and principles governing the behavior of people in the digital environment, and, most importantly, to create legal mechanisms to ensure compliance with these norms and principles.

In the world there are precedents of restrictions in the use of robotic programs to communicate with people. Thus, in California, a law prohibiting the use of bots in various online services (for example, chatbots), if the person (the owner of the bot) tries to mislead the interlocutor about the artificial nature of the bot. The law requires the owner of the program to disclose information that would be clearly formulated and located in a well-viewed place on the web-page. In addition, the computer program should be designed in such a way as to automatically inform the interlocutor that the bot interacts with him, and not a living person. The document comes into force on July 1, 2019.

Live communication between the student and the teacher, as well as contacts in the virtual environment should be balanced and determined by the curriculum as well as lectures and seminars, while the share of real and virtual time can be designed with due regard for the formation of competencies. The intention to reduce training only to the acquisition of skills and abilities hides the danger of forming utilitarian thinking and, as a consequence, a distorted worldview of students.

\section{Conclusion}

According to the results of the study, in the context of digitalization of the economy the proposals to improve state standards in the field of law in terms of updating competencies have been made, promising educational innovations have been identified, and ways to modernize the educational process have been proposed. In connection with the concerns expressed, it is also important to prevent the impoverishment of intellectual content in the pursuit of advanced digital form.

The solution of the problems identified in the article and other strategically important for Russia predetermines the need for scientific understanding of the phenomenon of digitalization of legal business education. It is obvious that taking into account the objectivity of the process of digitalization, as well as the huge potential of the introduction of technologies into the practice of law, legal education is particularly important, which should provide fundamental interdisciplinary training of professional personnel. This article has only outlined the most common vector of understanding of this global problem.

\section{References}

1. V.B. Vexov, Proceedings from "International and national trends and perspectives in forensic science” (Nizhny Novgorod, 2020)
2. Ministry of Public Education, Order "On Approval of the Target Model of Digital Educational Environment" (December 2, 2019, No 649) (Moscow, 2019)

3. V.A. Sadkov, M.V. Strokina, N.I. Baturina, N.V. Kvichiniy, Competitive Russia: Foresight Model of Economic and Legal Development in the Digital Age: Proceedings of the International Scientific Conference in Memory of Oleg Inshakov (19522018), 545-552 (Springer Nature, Cham, 2020) https://doi.org/10.1007/978-3-030-45913-0_64.

4. V.B. Vexov, Topical problems of practical orientation of the educational process in universities of the system of the Ministry of Internal Affairs of Russia, 35-40 (Volgograd, 2010)

5. G. Sidorov, Digital University: the use of digital technologies in modern educational institutions (2017), URL: https://www.itweek.ru/idea/article/detail.php?ID=1 92831 (date of access: 12.12.2020)

6. T.V. Deryugina, V.F. Borisova, Legal Concept $\mathbf{1 7}$ (4), 162-166 (2018)

7. O. P. Kazachenok, A.V. Lavrentyeva, Ubiquitous Computing and the Internet of Things: Prerequisites for the Development of ICT, 333-340 (Springer Science + Business Media, Cham, 2019)

8. O.P. Kazachenok, Competitive Russia: Foresight Model of Economic and Legal Development in the Digital Age: Proceedings of the International Scientific Conference in Memory of Oleg Inshakov (1952-2018), 407-413 (Springer Nature, Cham, 2020)

9. D.E. Prokudin, Information technologies in education and their role in the formation of manmade culture (Dissertation of doctor of philosophical sciences) (St. Petersburg, St. Petersburg State University, 2012)

10. Digital University, URL: https ://2018.edcr unch.ru/tracks/digital-university (date of access: 12.12.2020)

11. Government of the Russian Federation, Digital Economy Program (December 24, 2018, No 16) (Moscow, 2018)

12. M.V. Goncharova, O.V. Nikulina, I.V. Baltutite, A.N. Sadkov, Competitive Russia: Foresight Model of Economic and Legal Development in the Digital Age: Proceedings of the International Scientific Conference in Memory of Oleg Inshakov (19522018), 561-568 (Springer Nature, Cham, 2020)

13. D.A. Tokarev, V.A. Usanova, N. Kagalnitskova, V.A. Sandalova, Ubiquitous Computing and the Internet of Things: Prerequisites for the Development of ICT, 215-222 (Springer Science + Business Media, Cham, 2019)

14. T.V. Deryugina, Legal Framework for Bioeconomics and Biosafety: Monograph, 385-393 (NY: Prospekt, Moscow, 2020). 
15. T.N Bochkareva, A.R. Mubarakchina, Digital education in the Russia: realities and perspectives. Humanities (2019),

URL:

https://cyberleninka.ru/article/n/tsifrovoe-

obrazovanie-v-rossiyskoy-federatsii-realii-iperspektivy (date of access: 12.12.2020) 